\title{
Up-regulated Annexin A1 expression in gastrointestinal cancer is associated with cancer invasion and lymph node metastasis
}

\author{
YU SATO, KENSUKE KUMAMOTO, KATSUHARU SAITO, HIROKAZU OKAYAMA, \\ SUGURU HAYASE, YASUHIDE KOFUNATO, KOUTARO MIYAMOTO, IZUMI NAKAMURA, \\ SHINJI OHKI, YOSHIHISA KOYAMA and SEIICHI TAKENOSHITA
}

\begin{abstract}
Department of Organ Regulatory Surgery, Fukushima Medical University School of Medicine, Fukushima 960-1295, Japan
\end{abstract}
Received November 12, 2010; Accepted January 18, 2011

DOI: $10.3892 /$ etm.2011.210

\begin{abstract}
Annexin A1 (ANXA1) is a calcium-dependent phospholipid-linked protein, involved in anti-inflammatory effects, regulation of cellular differentiation, proliferation and apoptosis. In the present study, we investigated the expression of ANXA1 in gastric and colon cancer, and analyzed the relationship between ANXA1 expression and clinicopathological factors. ANXA1 mRNA expression in gastric and colon cancer tissues was not significantly changed compared to that in normal tissues. When ANXA1 protein expression was evaluated by immunohistochemical staining, ANXA1 expression was observed in 76 of 135 cases of gastric cancer $(56.3 \%)$, and correlations were found between ANXA1 expression and depth of wall invasion $(\mathrm{P}<0.001)$, lymphatic invasion $(\mathrm{P}=0.023)$, venous invasion $(\mathrm{P}=0.002)$, lymph node metastasis $(\mathrm{P}=0.001)$ and UICC stage $(\mathrm{P}<0.001)$. Disease-specific survival rate was significantly lower in cases with ANXA1 expression compared to that in cases without $(\mathrm{P}=0.0053)$. In colon cancer, ANXA1 expression was detected in 61 of 210 cases $(29.0 \%)$ and correlations were found with gender $(\mathrm{P}=0.038)$, lymphatic invasion $(\mathrm{P}=0.011)$, venous invasion $(\mathrm{P}=0.023)$, lymph node metastasis $(\mathrm{P}=0.042)$ and UICC stage $(\mathrm{P}=0.041)$. The disease-specific survival rate tended to be lower in cases with ANXA1 expression, although the differences were not statistically significant $(\mathrm{P}=0.6984)$. Our results indicate that up-regulated ANXA1 expression is involved in cancer invasion and lymph node metastasis. Furthermore, high levels of ANXA1 expression were implicated in poor prognosis of patients. ANXA1 may be applicable as a prognostic biomarker in gastric and colon cancer, and a potential target for treatment.
\end{abstract}

Correspondence to: Dr Seiichi Takenoshita, Department of Organ Regulatory Surgery, Fukushima Medical University School of Medicine, Fukushima 960-1295, Japan

E-mail: takenoss@fmu.ac.jp

Key words: Annexin A1, gastric cancer, colon cancer

\section{Introduction}

There has been evidence that inflammation is implicated in cancer development and progression. Various approaches have been used to clarify the relationship between inflammation and cancer. Recent reports have demonstrated that the gene expression profiles of cytokines related to inflammation in cancer tissues and the surrounding non-malignant tissues may be used as possible indexes of the association with clinicopathological factors and prognosis in liver and lung cancer $(1,2)$. In gastric cancer, it has been suggested that Helicobacter pylori is involved in the onset of cancer development through the induction of immunocompetent cells that evoke chronic inflammation and expression of immune-related cytokines (3). Although the major cause of colon cancer is considered to be an accumulation of cancer-related gene mutations, as represented by adenoma-carcinoma sequence and de novo types $(4,5)$, the involvement of cytokines in colitis-associated colon cancer coexisting with inflammatory enteritis has been reported (6). It is essential to analyze the balance of all cytokines related to inflammation which are intricately linked to cancer development and progression, and it is important to elucidate the function of inflammation-related molecules.

Annexin A1 (ANXA1), which belongs to the calciumdependent phospholipid-linked protein family, is associated with anti-inflammatory effects through the inhibition of phospholipase A2, including arachadonic acid (7). The functions of ANXA1 in tumor growth and development have been examined in various types of cancer, but are not clearly understood, since ANXA1 expression is differentially expressed in different cancer types, including esophageal cancer, pancreatic cancer, skin squamous cell carcinoma, colon cancer, cervical cancer, oral squamous cell carcinoma, prostate cancer, breast cancer and laryngeal squamous cell carcinoma (8-18). In the present study, we investigated ANXA1 expression in gastric and colon cancer, and analyzed the relationship between ANXA1 expression and clinicopathological factors and patient prognosis.

\section{Materials and methods}

Clinical samples of patients. For the analysis of mRNA expression, cancer tissues and adjacent normal mucosa were collected 
from 25 gastric cancer patients (19 males and 6 females) and 37 colon cancer patients (24 males and 13 females) who underwent surgery at our institute between 2003 and 2008 . The median age of the gastric and colon cancer patients was 73 and 64 years, respectively. Tissues were collected fresh during surgery, immediately frozen using liquid nitrogen and stored at $-80^{\circ} \mathrm{C}$ until total RNA was extracted. Formalin-fixed, paraffin-embedded specimens obtained from 135 patients with gastric cancer and 210 patients with colon cancer who underwent surgery at our institute between 1990 and 2007, including the cases mentioned above, were examined in this study. Regarding gastric cancer patients, the median age of the patients was 66 years. The carcinomas were staged according to UICC classification. These cases included stage I, 66 cases; stage II, 25 cases; stage III, 37 cases; and stage IV, 7 cases. In colon cancer, the median age of the patients was 67 years. The carcinomas were staged according to UICC classification. These cases included stage I, 40 cases; stage II, 82 cases; stage III, 60 cases; and stage IV, 28 cases. This study was performed in accordance with ethical guidelines for clinical research with the approval of our institutional ethics committee.

RNA extraction and quantitative reverse transcriptionpolymerase chain reaction (RT-PCR). Total RNA was extracted from $5-\mathrm{mm}^{2}$ blocks of each cancer and normal tissues obtained from resected specimens using TRIzol reagent (Invitrogen, Carlsbad, CA, USA) in accordance with the manufacturer's instruction manual. Complementary DNA (cDNA) was synthesized from $5 \mu \mathrm{g}$ of total RNA with random hexamer using the SuperScript III First-Strand Synthesis kit (Invitrogen). These cDNAs were used for the measurement of ANXA1 gene expression with a 7500 Real-Time PCR system (Applied Biosystems, Foster City, CA, USA). The level of mRNA expression for each tissue was normalized to that of $\beta$-actin. Probes for each gene were purchased from Applied Biosystems.

Immunohistochemical staining and evaluation. Paraffinembedded histological sections $(4 \mu \mathrm{m})$ were deparaffinized and washed with water, and then endogenous peroxidase activity was blocked with $0.3 \%$ hydrogen peroxide in methanol. After washing in PBS, blocking agent (Dako, Glostrup, Denmark) was used to regulate the non-specific reactivity. Anti-ANXA1 monoclonal antibodies (mouse IgG1, clone 29, 1:100; BD Biosciences) were allowed to react overnight at $4^{\circ} \mathrm{C}$ and after antigen-antibody reaction, diaminobenzidine (Envision; Dako) was used for visualization. Sections were counterstained with hematoxylin. The expression of ANXA1 protein was evaluated as positive when the nucleus and/or cytoplasm of cancerous and normal tissue indicated at least $5 \%$ dye-affinity when the total field of view was observed at $\mathrm{x} 40$ magnification. Assessment of the staining was evaluated by two independent pathologists without knowledge of the clinical status of the patients.

Statistical analysis. The paired t-test was used to determine the correlations between the amounts of ANXA1 mRNA expression in cancer and normal tissues. The Chi-square test or the Mann-Whitney U test was used to analyze the correlations
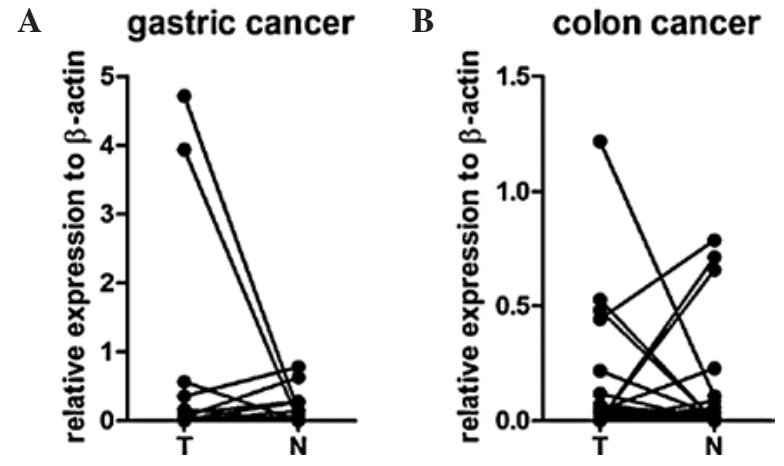

Figure 1. Real-time RT-PCR analyses of mRNA levels of ANXA1 in gastric and colon cancer. (A) ANXA1 mRNA level in cancerous tissue (T) and adjucent non-malignant mucosa $(\mathrm{N})$ in 25 patients with gastric cancer. (B) ANXA1 mRNA level in cancerous tissue (T) and adjucent non-malignant mucosa $(\mathrm{N})$ in 37 patients with colon cancer. $\beta$-actin served as the internal control.

between ANXA1 protein expression and each clinicopathological factor upon immunohistochemical staining. Survival analysis was performed using the log-rank test followed by the Kaplan-Meier method. We assumed there was a significant difference at $\mathrm{P}<0.05$. These analyses were performed using SPSS II for Windows 11.0.1J (Lead Technologies, Inc., Charlotte, NC, USA).

\section{Results}

ANXA1 mRNA expression in gastric and colon cancer. Levels of ANXA1 mRNA expression in the cancer and adjacent normal tissues obtained from 25 cases of gastric cancer and 37 cases of colon cancer were examined by quantitative RT-PCR. ANXA1 mRNA expression was differentially altered in cancer and normal tissues depending on the cases. As a result, there was no statistical significancy between the ANXA1 expression level of cancer tissue and that of normal tissues in the gastric and colon cancer tissues $(\mathrm{P}=0.2231$ and $\mathrm{P}=0.7331$, respectively) (Fig. 1).

Immunohistochemical determination of ANXA1 protein expression in gastric and colon cancer. ANXA1 protein expression in 135 gastric cancer and 210 colon cancer tissues was evaluated by immunohistochemical staining using an anti-ANXA1 antibody. ANXA1 expression was detected in the nucleus and cytoplasm of the malignant cells. ANXA1 expression was observed in 76 of 135 cases (56.3\%) in gastric cancer and 61 of 210 cases (29.0\%) in colon cancer (Fig. 2). The staining pattern in the cancerous region showed a tendency to be localized in the invasive lesion of the cancer tissue. ANXA1 expression was not detected in the normal mucosa in almost all cases, although ANXA1 expression of immunocompetent cells, such as lymphocytes in interstitial and connective tissues, including vessels, was sometimes observed, depending on the case.

Association of ANXA1 protein expression and clinicopathological factors. In gastric cancer, high ANXA1 protein expression showed significant positive correlations with depth of wall invasion $(\mathrm{P}<0.001)$, lymphatic invasion $(\mathrm{P}=0.023)$, 




Figure 2. Representative immunohistochemical staining pattern of ANXA1 expression in gastric and colon cancer. Immunohistochemical analysis of ANXA1 expression in gastric cancer (A-E) and colon cancer (F-J). (A) Strongly positive staining, $\geq 25 \%$ of tumor cells. (B) Moderately positive staining, $15-25 \%$ of tumor cells. (C) Weakly positive staining, $5-15 \%$ of tumor cells. (D) Negative staining, $<5 \%$ of tumor cells. (E) Normal gastric mucosa. (F) Strongly positive staining, $\geq 25 \%$ of tumor cells. (G) Moderately positive staining, $15-25 \%$ of tumor cells. (H) Weakly positive staining, $5-15 \%$ of tumor cells. (I) Negative staining, $<5 \%$ of tumor cells. (J) Normal colon mucosa. Magnification, $\mathrm{x} 40$.

venous invasion $(\mathrm{P}=0.002)$, lymph node metastasis $(\mathrm{P}=0.001)$ and UICC stage $(\mathrm{P}<0.001)$ (Table I). There were no correlations between ANXA1 protein expression and gender, age or histological differentiation. In colon cancer, high ANXA1 protein expression showed significant positive correlations with gender $(\mathrm{P}=0.038)$, lymphatic invasion $(\mathrm{P}=0.011)$, venous invasion $(\mathrm{P}=0.023)$, lymph node metastases $(\mathrm{P}=0.042)$ and UICC stage $(\mathrm{P}=0.041)$ (Table II). However, no significant correlations were observed between ANXA1 expression and age, tumor location, histological differentiation, depth of wall invasion and the presence of hepatic metastases.
Table I. Relationship between ANXA1 expression and clinicopathological findings in gastric cancer.

\begin{tabular}{|c|c|c|c|}
\hline \multirow[t]{2}{*}{ Characteristics } & \multicolumn{2}{|c|}{ ANXA1 expression } & \multirow[t]{2}{*}{ P-value } \\
\hline & $\begin{array}{c}\text { Negative } \\
(n=59)\end{array}$ & $\begin{array}{c}\text { Positive } \\
(n=76)\end{array}$ & \\
\hline Gender & & & 0.649 \\
\hline Male & $41(69 \%)$ & $50(66 \%)$ & \\
\hline Female & $18(31 \%)$ & $26(34 \%)$ & \\
\hline Age (years) & & & 0.610 \\
\hline$<60$ & $20(34 \%)$ & $29(38 \%)$ & \\
\hline$>60$ & $39(66 \%)$ & $47(62 \%)$ & \\
\hline Tumor differentiation & & & 0.368 \\
\hline Differentiated & $31(53 \%)$ & $34(45 \%)$ & \\
\hline Undifferentiated & $28(47 \%)$ & $42(55 \%)$ & \\
\hline Wall invasion & & & $<0.001$ \\
\hline $\mathrm{T} 1$ & $31(53 \%)$ & $12(16 \%)$ & \\
\hline $\mathrm{T} 2$ & $20(34 \%)$ & $34(45 \%)$ & \\
\hline $\mathrm{T} 3$ & $8(13 \%)$ & $30(39 \%)$ & \\
\hline Lymphatic invasion & & & 0.023 \\
\hline Absent & $16(27 \%)$ & $9(12 \%)$ & \\
\hline Present & $43(73 \%)$ & $67(88 \%)$ & \\
\hline Venous invasion & & & 0.002 \\
\hline Absent & $25(42 \%)$ & $14(18 \%)$ & \\
\hline Present & $34(58 \%)$ & $62(82 \%)$ & \\
\hline Lymph node metastasis & & & 0.001 \\
\hline Negative & $36(61 \%)$ & $25(33 \%)$ & \\
\hline Positive & $23(39 \%)$ & $51(67 \%)$ & \\
\hline UICC stage & & & $<0.001$ \\
\hline $\mathrm{I}$ & $40(68 \%)$ & $26(34 \%)$ & \\
\hline II & $8(14 \%)$ & $17(22 \%)$ & \\
\hline III & $9(15 \%)$ & $28(37 \%)$ & \\
\hline IV & $2(3 \%)$ & $5(7 \%)$ & \\
\hline
\end{tabular}

Relationship between ANXA1 expression and prognosis in gastric and colon cancer. The disease-specific survival rate of the gastric cancer patients with high ANXA1 expression was significantly lower as compared to the patients without ANXA1 expression $(\mathrm{P}=0.0053)$ (Fig. 3A). However, this difference in expression was not an independent predictor on multivariate analysis using the Cox regression model. In colon cancer, the disease-specific survival rate of the patients with high ANXA1 expression tended to be lower than that in patients without ANXA1 expression, although this was not statistically significant ( $\mathrm{P}=0.6984)$ (Fig. 3B).

\section{Discussion}

ANXA1 is a calcium-dependent phospholipid-linked protein with a molecular weight of $37 \mathrm{kDa}$ that shows phospholipase A2 inhibitory activity and is derived from glucocorticoid (19). ANXA1 is an endogenous anti-inflammatory protein with a number of biological functions, such as cell adhesion, inhibition of migration, inflammation, phagocytosis, proliferation and apoptosis $(20,21)$. ANXA1 also has an important 
Table II. Relationship between ANXA1 expression and clinicopathological findings in colon cancer.

\begin{tabular}{|c|c|c|c|}
\hline \multirow[t]{2}{*}{ Characteristics } & \multicolumn{2}{|c|}{ ANXA1 expression } & \multirow[t]{2}{*}{ P-value } \\
\hline & $\begin{array}{l}\text { Negative } \\
(n=149)\end{array}$ & $\begin{array}{c}\text { Positive } \\
(n=61)\end{array}$ & \\
\hline Gender & & & 0.038 \\
\hline Male & $94(63 \%)$ & $29(48 \%)$ & \\
\hline Female & $55(37 \%)$ & $32(52 \%)$ & \\
\hline Age (years) & & & 0.816 \\
\hline$<60$ & $44(30 \%)$ & $19(31 \%)$ & \\
\hline$>60$ & $105(70 \%)$ & $42(69 \%)$ & \\
\hline Tumor location & & & 0.180 \\
\hline Proximal & $44(30 \%)$ & $24(39 \%)$ & \\
\hline Distant & $61(40 \%)$ & $17(28 \%)$ & \\
\hline Rectum & $44(30 \%)$ & $20(33 \%)$ & \\
\hline Tumor differentiation & & & 0.719 \\
\hline Well & $67(45 \%)$ & $28(46 \%)$ & \\
\hline Moderate & $68(46 \%)$ & $24(39 \%)$ & \\
\hline Poor & $4(3 \%)$ & $2(3 \%)$ & \\
\hline Mucinous & $10(6 \%)$ & $7(12 \%)$ & \\
\hline Wall invasion & & & 0.274 \\
\hline $\mathrm{T} 1$ & $18(12 \%)$ & $4(7 \%)$ & \\
\hline $\mathrm{T} 2$ & $18(12 \%)$ & $7(11 \%)$ & \\
\hline $\mathrm{T} 3$ & $103(70 \%)$ & $45(74 \%)$ & \\
\hline $\mathrm{T} 4$ & $10(6 \%)$ & $5(8 \%)$ & \\
\hline Lymphatic invasion & & & 0.011 \\
\hline Absent & $38(26 \%)$ & $6(10 \%)$ & \\
\hline Present & $111(74 \%)$ & $55(90 \%)$ & \\
\hline Venous invasion & & & 0.023 \\
\hline Absent & $35(23 \%)$ & $6(10 \%)$ & \\
\hline Present & $114(77 \%)$ & $55(90 \%)$ & \\
\hline Lymph node metastasis & & & 0.042 \\
\hline Negative & $97(65 \%)$ & $30(49 \%)$ & \\
\hline Positive & $52(35 \%)$ & $31(51 \%)$ & \\
\hline Hepatic metastasis & & & 0.404 \\
\hline Negative & $131(88 \%)$ & $51(84 \%)$ & \\
\hline Positive & $18(12 \%)$ & $10(16 \%)$ & \\
\hline UICC stage & & & 0.041 \\
\hline $\mathrm{I}$ & $32(21 \%)$ & $8(13 \%)$ & \\
\hline II & $61(41 \%)$ & $21(35 \%)$ & \\
\hline III & $38(26 \%)$ & $22(36 \%)$ & \\
\hline IV & $18(12 \%)$ & $10(16 \%)$ & \\
\hline
\end{tabular}

role in tumor development and progression, although the exact mechanisms in cancer remain unknown. To date, numerous reports suggest that ANXA1 is differentially expressed depending on cancer types. In fact, ANXA1 was found to be up-regulated in esophageal cancer (8), pancreatic cancer (9), skin squamous cell carcinoma (10) and colon cancer (11), and down-regulated in cervical cancer (12), oral squamous cell carcinoma (13), prostate cancer (14), breast cancer (15-17) and laryngeal squamous cell carcinoma (18). For example, high
A

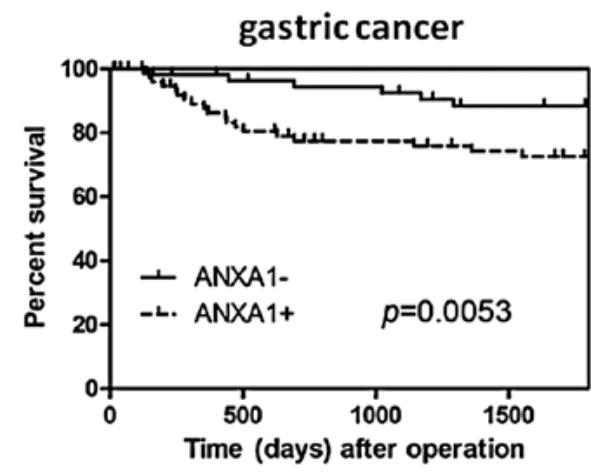

B

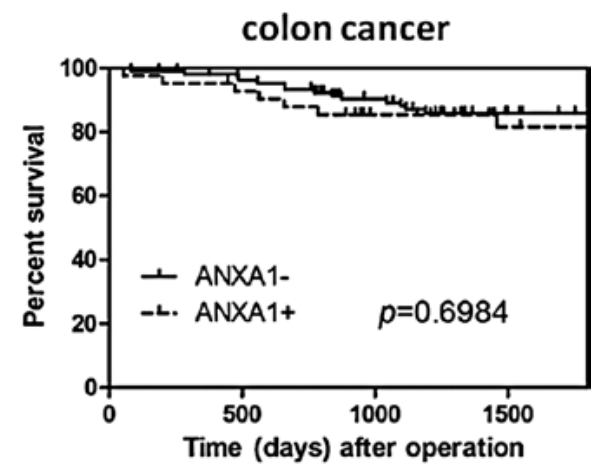

Figure 3. Kaplan-Meier curves of overall survival in patients with ANXA1positive and ANXA1-negative expression in gastric and colon cancer. (A) In patients with gastric cancer, ANXA1-positive cases had significantly shorter overall survival than in ANXA1-negative cases. (B) No significance was detected between ANXA1-positive and ANXA1-negative cases in colon cancer.

levels of ANXA1 expression were detected in approximately $40 \%$ of cases of esophageal and gastroesophageal junction adenocarcinoma and were correlated with the progression of $\mathrm{T}$ factor and distant metastases (8). The studies concluded that ANXA1 is an independent prognostic factor for patient survival. Regarding breast cancer, suppression of ANXA1 expression was found to be related to cancer development and progression (15-17). This discrepancy indicates that a physiological range of ANXA1 levels is important to maintain cellular homeostasis. In particular, the evaluation of ANXA1 expression has not been accurately carried out in gastric and colon cancer. In the present study, we found that ANXA1 protein expression was up-regulated in approximately $60 \%$ of gastric cancer and $30 \%$ of colon cancer tissues, and high expression of ANXA1 was associated with advanced stage, including deeper wall invasion, lymphatic invasion, venous invasion and lymph node metastasis. Consequently, ANXA1 expression was implicated in poor prognosis. Our results suggest that ANXA1 plays an essential role in tumor growth, invasion and metastasis.

There are only a few reports on ANXA1 in gastric and colon cancer. A previous report found that the lack of ANXA1 protein expression was correlated with the degree of $\mathrm{T}$ factor progression, lymph node metastasis, advanced stage and histological low differentiation by microarray analysis using tissue samples obtained from gastric cancer patients, suggesting that ANXA1 is a negative biomarker of gastric cancer growth and development (22). Although the results conflict with our data, various reasons explaining this discrepancy include the experimental condition and the different antibody used for 
immunohistochemical staining. Therefore, whether ANXA1 expression is up- or down-regulated in gastric cancer is difficult to determine. In fact, similar findings were recognized in breast cancer. Our findings provide new insight to the association between ANXA1 expression and gastric cancer. Regarding colon cancer, one supportive study found increased ANXA1 protein expression in primary and metastatic lesions when compared to the normal mucosa. However, no correlation was found between the extent of ANXA1 expression and tumor stage (11).

Recently, the result of an ANXA1-knockout mice study suggested that tumor growth and metastasis using cancer cell lines were significantly decreased in ANXA1-knockout mice compared to ANXA1 wild-type mice (23). Furthermore, ANXA1 acts directly on the EGFR to regulate the EGFR/ Ras pathway, and binds to the EGFR adaptor protein Grb2 and increases Ras activity, resulting in the activation of the mitogen-activated protein kinase extracellular signalregulated kinase (24). An in vitro experiment of a colorectal cancer cell line, knocked down for ANXA1 expression using an siRNA method, found attenuated cellular invasion (25). These data indicate that ANXA1 expression may be associated with tumor growth, tumor invasion and metastasis, and may support our current results that ANXA1 expression is up-regulated in a subset of gastric and colon cancer and is significantly associated with lymphatic invasion, venous invasion, lymph node metastases and UICC stage in both gastric and colon cancer.

When ANXA1 mRNA was measured in the cancer and non-cancer tissues, no significant differences were observed in the ANXA1 expression level in either type of cancer. Although the number of cases included in the study was small, we realized that it was difficult to evaluate the ANXA1 expression level accurately in cancer cells as ANXA1 was expressed non-specifically in infiltrating cells of interstitial tissues as determined by immunohistochemical staining. Therefore, immunohistochemical staining is a more accurate method than real-time PCR for evaluating ANXA1 expression in clinical samples.

Our results indicate that the clinical significance of ANXA1 expression is related to tumor invasion and metastasis, resulting in poor prognosis. Thus, ANXA1 expression may be a useful marker to predict malignant potential of gastric and colon cancer. Further investigation is needed before its application as a target therapy for cancer.

\section{References}

1. Budhu A, Forgues M, Ye QH, et al: Prediction of venous metastases, recurrence, and prognosis in hepatocellular carcinoma based on a unique immune response signature of the liver microenvironment. Cancer Cell 10: 99-111, 2006.

2. Seike M, Yanaihara N, Bowman ED, Zanetti KA, Budhu A, Kumamoto K, Mechanic LE, Matsumoto S, Yokota J, Shibata T, Sugimura H, Gemma A, Kudoh S, Wang XW and Harris CC: Use of a cytokine gene expression signature in lung adenocarcinoma and the surrounding tissue as a prognostic classifier. J Natl Cancer Inst 99: 1257-1269, 2007.

3. Bronte-Tinkew DM, Terebiznik M, Franco A, Ang M, Ahn D, Mimuro H, Sasakawa C, Ropeleski MJ, Peek RM Jr and Jones NL: Helicobacter pylori cytotoxin-associated gene A activates the signal transducer and activator of transcription 3 pathway in vitro and in vivo. Cancer Res 69: 632-639, 2009.

4. Muto T, Bussey HJ and Morson BC: The evolution of cancer of the colon and rectum. Cancer 36: 2251-2270, 1975.
5. Minamoto T, Sawaguchi K, Mai M, Yamashita N, Sugimura T and Esumi H: Infrequent K-ras activation in superficial-type (flat) colorectal adenomas and adenocarcinomas. Cancer Res 54: 2841-2844, 1994

6. Grivennikov S, Karin E, Terzic J, Mucida D, Yu GY, Vallabhapurapu S, Scheller J, Rose-John S, Cheroutre H, Eckmann L and Karin M: IL-6 and Stat3 are required for survival of intestinal epithelial cells and development of colitisassociated cancer. Cancer Cell 15: 103-113, 2009.

7. Lim LH and Pervaiz S: Annexin 1: the new face of an old molecule. FASEB J 21: 968-975, 2007.

8. Wang KL, Wu TT, Resetkova E, Wang H, Correa AM, Hofstetter WL, Swisher SG, Ajani JA, Rashid A, Hamilton SR and Albarracin CT: Expression of annexin A1 in esophageal and esophagogastric junction adenocarcinomas: association with poor outcome. Clin Cancer Res 12: 4598-4604, 2006.

9. Bai XF, Ni XG, Zhao P, Liu SM, Wang HX, Guo B, Zhou LP, Liu F, Zhang JS, Wang K, Xie YQ, Shao YF and Zhao XH: Overexpression of annexin 1 in pancreatic cancer and its clinical significance. World J Gastroenterol 10: 1466-1470, 2004.

10. Hummerich L, Müller R, Hess J, Kokocinski F, Hahn M, Fürstenberger G, Mauch C, Lichter P and Angel P: Identification of novel tumour-associated genes differentially expressed in the process of squamous cell cancer development. Oncogene 25: 111-121, 2006.

11. Duncan R, Carpenter B, Main LC, Telfer C and Murray GI: Characterisation and protein expression profiling of annexins in colorectal cancer. Br J Cancer 98: 426-433, 2008.

12. Wang LD, Yang YH, Liu Y, Song HT, Zhang LY and Li PL: Decreased expression of annexin A1 during the progression of cervical neoplasia. J Int Med Res 36: 665-672, 2008.

13. Lin CY, Jeng YM, Chou HY, Hsu HC, Yuan RH, Chiang CP and Kuo MY: Nuclear localization of annexin A1 is a prognostic factor in oral squamous cell carcinoma. J Surg Oncol 97: 544-550, 2008

14. Kang JS, Calvo BF, Maygarden SJ, Caskey LS, Mohler JL and Ornstein DK: Dysregulation of annexin I protein expression in high-grade prostatic intraepithelial neoplasia and prostate cancer. Clin Cancer Res 8: 117-123, 2002.

15. Chuthapisith S, Bean BE, Cowley G, Eremin JM, Samphao S, Layfield R, Kerr ID, Wiseman J, El-Sheemy M, Sreenivasan T and Eremin O: Annexins in human breast cancer: possible predictors of pathological response to neoadjuvant chemotherapy. Eur J Cancer 45: 1274-1281, 2009.

16. Cao Y, Li Y, Edelweiss M, Arun B, Rosen D, Resetkova E, Wu Y, Liu J, Sahin A and Albarracin CT: Loss of annexin A1 expression in breast cancer progression. Appl Immunohistochem Mol Morphol 16: 530-534, 2008.

17. Shen D, Nooraie F, Elshimali Y, Lonsberry V, He J, Bose S, Chia D, Seligson D, Chang HR and Goodglick L: Decreased expression of annexin A1 is correlated with breast cancer development and progression as determined by a tissue microarray analysis. Hum Pathol 37: 1583-1591, 2006.

18. lves VA, Nonogaki S, Cury PM, Wünsch-Filho V, de Carvalho MB, Michaluart-Júnior P, Moyses RA, Curioni OA, Figueiredo DL, Scapulatempo-Neto C, Parra ER, Polachini GM, Silistino-Souza R, Oliani SM, Silva-Júnior WA and Nobrega FG; Head and Neck Genome Project/GENCAPO, Tajara EH and Zago MA: Annexin A1 subcellular expression in laryngeal squamous cell carcinoma. Histopathology 53: 715-727, 2008.

19. Kim SW, Rhee HJ, Ko J, Kim YJ, Kim HG, Yang JM, Choi EC and Na DS: Inhibition of cytosolic phospholipase A2 by annexin I. Specific interaction model and mapping of the interaction site. J Biol Chem 276: 15712-15719, 2001.

20. Gerke V and Moss SE: Annexins: from structure to function. Physiol Rev 82: 331-371, 2002.

21. Parente L and Solito E: Annexin 1: more than an antiphospholipase protein. Inflamm Res 53: 125-132, 2004

22. Yu G, Wang J, Chen Y, Wang X, Pan J, Li Q and Xie K: Tissue microarray analysis reveals strong clinical evidence for a close association between loss of annexin A1 expression and nodal metastasis in gastric cancer. Clin Exp Metastasis 25: 695-702, 2008.

23. Yi M and Schnitzer JE: Impaired tumor growth, metastasis, angiogenesis and wound healing in annexin A1-null mice. Proc Natl Acad Sci USA 106: 17886-17891, 2009.

24. Grewal T and Enrich C: Annexins - modulators of EGF receptor signalling and trafficking. Cell Signal 21: 847-858, 2009.

25. Babbin BA, Lee WY, Parkos CA, Winfree LM, Akyildiz A, Perretti $\mathrm{M}$ and Nusrat A: Annexin I regulates SKCO-15 cell invasion by signaling through formyl peptide receptors. J Biol Chem 281: 19588-19599, 2006. 